\section{Dating of the Santorini eruption}

SIR - I would like to comment on the radiocarbon dating section of the recent paper by Hammer et al. ${ }^{1}$, and particularly on the comments in the accompanying News and Views article by Cadogan ${ }^{2}$, on dating the Santorini eruption.

First, the conclusion of Cadogan, that "Taking everything into account, a date of the sixteenth century $\mathrm{BC}$ seems the most likely", is not correct. Only traditional pottery studies support this view ${ }^{2-4}$. Moreover, there are several plausible contrary interpretations using traditional archaeological evidence (refs 5, 6). All other evidence currently points to a date of the later seventeenth century $\mathbf{B C}^{1,5}$. Cadogan argues that because three independent scientific techniques (ice-core, dendrochronology and radiocarbon) produce results which vary by only 30 years over 3,600 years, they should all be rejected. Instead, he asks us to accept a subjective archaeological date a century later: a date derived from the disputed comparison of art designs, or correlations from dubiously datable finds, with Egyptian pharaonic dates (themselves debated).

Concerning the radiocarbon evidence, where it is not possible to raise doubts of relevance, further analysis is desirable. Hammer et al. ' consider a set of 14 shortlife dates associated with the destruction of the site of Akrotiri on Thera (Santorini). These dates should provide a range shortly before the eruption, which engulfed the site. They reject only three dates as outliers, and thus include for analysis three dates from undersized samples with their attendant large errors, and some others which even a glance at their Table 1 suggests are aberrant (P-2792, P-2794). The unstated result is that their weighted average of $1,359 \pm 17$ carbon-14 yr BC has an acceptable, but uncomfortably high test statistic $\left(T^{\prime}\right.$, following ref. 7 ; with \pm 14 yr calibration error - allowed for here and not again at calibration), of 15.12 , compared with $\chi_{13: 0.05}^{2}=22.36$. If a statistical clustering procedure were used ${ }^{8}$, then of the 17 original dates, a central set of 12 dates (excluding P-2792 and P-2794 from Table 1 of ref. 1) is derived, with a weighted average of $3,321 \pm 18 \mathrm{yr}$ before present (BP) $\left(T^{\prime}=4.1<\chi_{110.05}^{2}=19.7\right)$. The calibrated date ${ }^{9}$ is about $1622 \mathrm{BC}$, the range $\pm 1 \sigma=\sim 1639-09,1552-45$ BC. Moreover, if the two remaining dates from undersized samples were removed (P-2793, P-2795), together with the least coherent date of the above twelve, P-1885 (which is the only date not to include the weighted average within its $1 \sigma$ error) then a significant, coherent group of nine (of seventeen) dates emerges with a weighted average of $3,331 \pm 20 \mathrm{yr}$ BP. The calibrated age is about $1629 \mathrm{BC}$, the range at $\pm 1 \sigma=$ $\sim$ 1675-12 BC. The weighted averages of Hammer et al. ${ }^{1}$ (and of Aitken ${ }^{10}$ ) are thus too low because they uncritically include the aberrant $(>2.5 \sigma$ deviation) low, small standard error (and hence statistically biasing) date of P-2794 (also P-1885; a problem only partly countered by Hammer et al. by the inclusion of the aberrantly

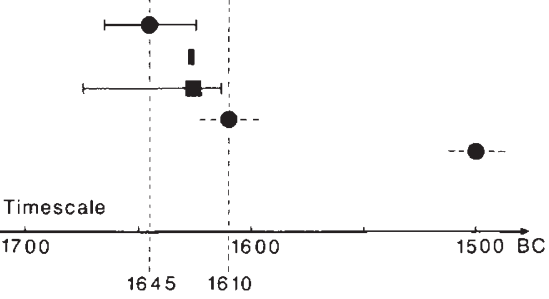

Graphic representation of the different chronological evidence relating to the calendar $\mathrm{BC}$ date of the Bronze Age eruption of the Santorini volcano. From the top, symbols indicate: icecore date ${ }^{1}$; frost-ring date $^{12}$; radiocarbon; revisionist archaeological ${ }^{5}$; and traditional archaeological $^{3,4}$

high P-2792, because of its statistically mitigating large $\sigma$ ).

The calibrated date ranges derived above clearly indicate that the eruption occurred in the seventeenth century $\mathrm{BC}$ (see also ref. 11). Moreover, in the former case, the small mid-sixteenth century $\mathrm{BC}$ date range is statistically unlikely, as the appropriate section of the calibration curve mainly lies outside the total $\sigma$ boundaries of the weighted average'.

Hence, regarding the dating of the Bronze Age eruption of Santorini, I conclude as follows. Frost-ring damage suggests a date of $1628-26 \mathrm{BC}^{12}$. Radiocarbon date analysis supports an entirely compatible seventeenth century $\mathrm{BC}$ date range of about $1675-09 \mathrm{BC}$, with the calibrated mean at about 1629-22 BC (see also ref. 11). Ice-core analysis suggests a date range of $1645 \pm 20 \mathrm{BC}^{1}$, again consistent within its very small (over 3,600 years) error margin. Recent re-interpretations of the archaeological evidence ${ }^{5,6}$ suggest similar date ranges. Only the traditional archaeological interpretation is at odds (see refs $2-4$ ). Taking everything into account, the most likely date of the eruption is the later seventeenth century $\mathrm{BC}$. Thorough re-consideration of the (inconsistent) traditional Aegean Bronze Age pottery chronology now seems necessary. It is to be hoped that dates from atomic mass spectrometry soon to be obtained from seeds on Thera, will finally resolve this controversy.

\section{Department of Archaeology}

Sturt W. Manning

\section{and Prehistory,}

University of Sheffield,

Sheffield S10 2TN, UK
Hammer et al. RePly - We do not completely agree with Manning's comments on our treatment of the radiocarbon dates ${ }^{1}$. Certainly one can treat the data further statistically, and also try to exclude further dates, but only at the risk of introducing a bias in the selection. We took the conservative view of excluding only the three obvious outliers. It is thus not justified to exclude dates made on undersized samples just because they are undersized and have a large error. If weighted means are calculated, such dates only carry little weight $\left(\mathrm{P}=1 / \sigma^{2}\right)$, but they ought to be included. This applies for instance to P-2792 "which even a glance at their Table 1 suggests are aberrant". The date is not aberrant by normal statistical evaluation; it deviates by $2 \sigma$ from the calculated mean, which is an expectable deviation in a set of 14 dates.

If the exclusion of radiocarbon dates is carried as far as proposed by Manning, and also by Betancourt and Michael ${ }^{11}$, we arrive at a set of nine dates, which no longer show a normal statistical scatter, as all the remaining dates are within $1 \sigma$ from the mean. It was to avoid such a situation, which might be criticized as biased, that we restricted our statistical treatment of the radiocarbon dates, although we were aware that additional exclusion of dates would give a mean radiocarbon age in closer agreement with our ice-core date.

The main purpose of our paper was to show that ice-core dating, radiocarbon dates, and a tree-ring (frost-ring) date all point to a seventeenth century $\mathrm{BC}$ date for the Santorini eruption. Of these we consider the ice-core date as the most probable, because the acidity signal in the $1645-44 \mathrm{BC}$ ice layers is clearly related to a major volcanic eruption, whereas the frost damage at 1628-26 $\mathrm{BC}$, though carrying a statistical probability of being related to a volcanic eruption ${ }^{12}$, could have been caused by climatic impacts other than volcanism. We consider it premature to fix the date more precisely than in our paper, by radiocarbon or other methods. This is why we left a question mark at the proposed date of $1645 \pm 7 \mathrm{yr} \mathrm{BC}$.

C.U. Hammer and H.B. Clausen Geophysical Institute, University

of Copenhagen, Haraldsgate 6 ,

DK-2200 Copenhagen, Denmark

W.L. FRIEDRICH

Geological Institute, Aarhus University,

C.F. Møllersalle 120, DK-8000 Aarhus C, Denmark

H. TAUBER

Radiocarbon Dating Laboratory,

National Museum, Ny Vestergade 10, DK-1471 Copenhagen K, Denmark

CADOgAN REPLIES - My remarks in my News and Views article ${ }^{2}$ on the paper by Hammer et al.' were too cryptic. I will go through the arguments again. First, 